\title{
Prevalence of small airways dysfunction in asthma with-and without-fixed airflow obstruction and chronic obstructive pulmonary disease
}

\author{
Prapaporn Pornsuriyasak, ${ }^{1}$ Supattra Khiawwan, ${ }^{1}$ Sasivimol Rattanasiri, ${ }^{2}$ Nattawut Unwanatham,${ }^{2}$ Tananchai Petnak ${ }^{1}$
}

\begin{abstract}
Background: Small airways dysfunction (SAD) is not uncommon in asthma without fixed airflow obstruction (FAO).

Objectives: We aimed to determine if SAD in non-FAO asthma is different from FAO-asthma and COPD.

Methods: Cases of obstructive airway diseases who underwent spirometry, plethysmography, and impulse oscillometry [resistance at $5 \mathrm{~Hz}\left(\mathrm{R}_{5}\right)$ and at $20 \mathrm{~Hz}\left(\mathrm{R}_{20}\right)$, peripheral resistance $\left(\mathrm{R}_{5}-\mathrm{R}_{20}\right)$, and reactance area $(A X)$ ] were reviewed, and classified as; 1) COPD, 2) FAO-asthma, and 3) non-FAO asthma. FAO was defined as post-bronchodilator (post-BD) $\mathrm{FEV}_{1} / \mathrm{FVC}<0.7$. SAD was considered if 1$) \mathrm{RV} / \mathrm{TLC} \geq 40 \%$, or 2 ) post-BD $\mathrm{R}_{5}-\mathrm{R}_{20} \geq 0.075 \mathrm{kPa} \cdot \mathrm{L}^{-1} \mathrm{~s}$.

Results: A total of 73 patients (22 COPD, 24 FAO-asthma, and 27 non-FAO asthma) were analysed. RV/TLC ratio was higher in FAO-asthma and COPD $(45 \pm 5 \%$ and $42 \pm 8 \%)$ than in non-FAO asthma $(32 \pm 8 \%), p<0.001$. Post-BD values of $\mathrm{R}_{5}-\mathrm{R}_{20}$ and $\mathrm{AX}$ (median; range) were higher in FAO-asthma $(0.17 ; 0.08,0.47,13.24 ; 6.52,82.11)$ than in nonFAO asthma $(0.11 ; 0.03,0.23,8.63 ; 2.40,22.02), p=0.007$ and $p=0.017$, respectively. The prevalence of SAD among diagnosis group by RV/TLC criterion was different (95\%, 59\%, and 15\% in FAO-asthma, COPD, and non-FAO asthma, $p<0.001)$, but those were not observed by $\mathrm{R}_{5}-\mathrm{R}_{20}$ criterion $(95 \%, 68 \%$, and $77 \%, p=0.052)$.
\end{abstract}

Conclusion: SAD in non-FAO asthma was less prevalent than FAO-asthma and COPD.

Key words: air trapping, asthma, COPD, fixed airflow obstruction, impulse oscillometry, small airways

\footnotetext{
Affiliations:

${ }^{1}$ Division of Pulmonary and Critical Care, Department of Medicine, Faculty of Medicine, Ramathibodi Hospital, Mahidol University, Bangkok, Thailand

${ }^{2}$ Section for Clinical Epidemiology and Biostatistics, Ramathibodi Hospital, Mahidol University, Bangkok, Thailand
}

\section{Corresponding author:}

Prapaporn Pornsuriyasak

Division of Pulmonary and Critical Care, Department of Medicine Ramathibodi Hospital, Mahidol University

270 Rama 6 Road, Ratchatewi, Bangkok, Thailand 10400

E-mail: pprapaporn@gmail.com

\section{Introduction}

The small airway plays a role in the pathogenesis of asthma and chronic obstructive pulmonary disease (COPD). In asthma, inflammation and functional alterations of the small airways are associated with the severity of asthma. ${ }^{1-3}$ In COPD, air trapping and small airway wall thickening are associated with the progression of disease. ${ }^{4}$ In contrast to airway obstruction in asthma, the major site of increased airway

$\begin{array}{ll}\text { Abbreviations } \\ \mathrm{FEV}_{1} \quad \text { forced expiratory volume in } 1 \mathrm{~s} \\ \mathrm{FVC} & \text { forced vital capacity } \\ \mathrm{R}_{5} & \text { respiratory resistance at } 5 \mathrm{~Hz} \\ \mathrm{R}_{20} & \text { resistance at } 20 \mathrm{~Hz} \\ \mathrm{X}_{5} & \text { respiratory system reactance at } 5 \mathrm{~Hz} \\ \text { Fres } & \text { resonant frequency } \\ \mathrm{R}_{5}-\mathrm{R}_{20} & \text { difference between } \mathrm{R}_{5} \text { and } \mathrm{R}_{20} \\ \mathrm{AX} & \text { reactance area } \\ \mathrm{TLC} & \text { total lung capacity } \\ \mathrm{RV} & \text { residual volume } \\ \mathrm{Raw} & \text { airway resistance (plethysmography) }\end{array}$

resistance in COPD is the small airways. ${ }^{5,6}$ Small airway resistance makes up about $60 \%$ of total resistance in advanced stages of COPD. ${ }^{6}$ The overall prevalence of small airway dysfunction (SAD) was reported in $50-60 \%$ in asthma, ${ }^{7}$ and varied in COPD, depending on the severity of airway obstruction (18\% in mild, $27 \%$ in moderate, $41 \%$ in severe, and $53 \%$ in very severe obstruction). ${ }^{8}$ These studies used differing 
inclusion characteristics and recruited patients with a broad range of severity, with different techniques to assess the small airways; for example, impulse oscillometry (IOS), spirometry, plethysmography, multiple-breath nitrogen washout. IOS has several advantages over spirometry and plethysmography as it does not require effort to force expiration that may affect small airway closure, and can differentiate if an increase in the total airway resistance [resistance at $5 \mathrm{~Hz}\left(\mathrm{R}_{5}\right)$ ] is at central [resistance at $20 \mathrm{~Hz},\left(\mathrm{R}_{20}\right)$ ] or at peripheral [difference between $R_{5}$ and $R_{20}\left(R_{5}\right.$ minus $\left.R_{20}, R_{5}-R_{20}\right)$ ], with the higher values corresponding to increased small airway resistance. Regarding other parameters of IOS, reactance at $5 \mathrm{~Hz}\left(\mathrm{X}_{5}\right)$ and reactance area $(\mathrm{AX})$ denote non-uniform distribution of ventilation due to small airway closure and/or lung stiffness. Resonant frequency (Fres) is oscillation frequency at which the reactance equals to zero. The higher Fres (normal, 7-12 $\mathrm{Hz}$ ) also designates the higher non-uniform distribution of ventilation due to small airway closure and/or lung stiffness. ${ }^{9}$ The interpretation of SAD requires a combination of these parameters. Despite using the same technique such as IOS, threshold or cut-point to define SAD among studies varied. We hypothesized that newly diagnosed asthma without FAO would disclose a lesser extent of SAD than asthma with FAO and COPD. We aimed to test that the prevalence of SAD in non-FAO asthma (newly-diagnosed asthma) is different from those of FAO-asthma and COPD by using the different physiologic criteria that were 1) ratio of $\mathrm{RV} / \mathrm{TLC} \geq 40 \%,{ }^{10}$ or 2 ) post-bronchodilator value of $\mathrm{R}_{5}-\mathrm{R}_{20} \geq 0.075 \mathrm{kPa} . \mathrm{L}^{-1} \mathrm{~s}^{11}$ The secondary objective was to investigate the associations between RV/TLC ratio and IOS parameters and types of diagnosis.

\section{Methods \\ Patients}

The present study was approved by the Ethics Committee of Ramathibodi Hospital, Mahidol University (ID 08-60-69). The study was retrospectively conducted by reviewing medical records and pulmonary function data of the patients who referred to our pulmonary function laboratory from 2015 to 2016. The patients were categorized into 3 groups; stable COPD; asthma with fixed airflow obstruction (FAO); newly diagnosed asthma who had no FAO and were naïve to anti-asthma treatment and had roughly comparable age with the first 2 groups. Each group was diagnosed by the following criteria. A diagnosis of asthma was made based on the Global Initiative for Asthma guideline 2012. ${ }^{12}$ Diagnosis of asthma was based on either criterion; 1) presence of history of childhood asthma, or 2) presence of previously documented varible airflow obstruction to inhaled salbutamol. Asthmatic patients included were never-smokers or had a non-significant smoking history (less than 10 pack-years). Diagnosis of COPD was based on the Global Initiative for Chronic Obstructive Lung Disease guideline 2014. ${ }^{13}$ The COPD patients included had a smoking history of at least 10 pack-years. The presence of FAO, both in patients with asthma and COPD, was defined as $\mathrm{FEV}_{1} / \mathrm{FVC}$ of less than 0.7 and $\mathrm{FEV}_{1}$ less than $80 \%$ predicted after inhalations of $400 \mu \mathrm{g}$ of salbutamol via spacer. The patients who had suffered from respiratory tract infection or had history of exacerbation within 8 weeks were excluded.
Asthma control and COPD quality of life were assessed by asthma control test (ACT) and COPD assessment test (CAT) from the record at the visit for pulmonary function laboratory. All patients were reviewed for allergic sensitization by either history of atopy or positive specific IgE to airborne allergen if available.

\section{Spirometry, lung volumes, and impulse oscillometry}

All patients underwent the measurement of impulse oscillometry (IOS) (Jaeger MasterScreen version 4.5, E. Jaeger $\mathrm{GmbH}$, Wurzburg, Germany). The IOS was performed according to standard recommendation. ${ }^{14}$ Briefly, subjects wore noseclips, with their cheeks supported and the measurement was performed during stable tidal breathing for 30 seconds. Each subject performed an optimum of three reproducible maneuvers of which the coefficient of variation was within $10 \%$, and the average of the three chosen maneuvers was used for analysis. The following parameters were recorded; respiratory resistance at $5 \mathrm{~Hz}\left(\mathrm{R}_{5}\right)$; resistance at $20 \mathrm{~Hz}\left(\mathrm{R}_{20}\right)$; the respiratory system reactance $(\mathrm{Xrs})$ at $5 \mathrm{~Hz}\left(\mathrm{X}_{5}\right)$; resonant frequency (Fres). The difference between $\mathrm{R}_{5}$ and $\mathrm{R}_{20}\left(\mathrm{R}_{5}-\mathrm{R}_{20}\right)$ was calculated. The respective change in Xrs, termed reactance area $(\mathrm{AX})$, was calculated as the integrated area of all Xrs data below zero from $5 \mathrm{~Hz}$ up to the Fres. Following IOS testing, spirometry (forced expiratory volume in $1 \mathrm{~s}\left(\mathrm{FEV}_{1}\right)$, forced vital capacity (FVC), and lung volumes measurement [total lung capacity (TLC), residual volume (RV), ratio of RV/ TLC], and airway resistance (Raw), were measured in a constant volume plethysmograph (CardinalHealth, Yorba Linda, CA, USA). IOS and spirometry were repeated 15 minutes after inhalations of $400 \mu \mathrm{g}$ of salbutamol via spacer. Equipment was calibrated daily. The predicted values for spirometry and for lung volumes were selected. ${ }^{15,16}$ Small airway dysfunction was defined by the following criteria: 1) the ratio of RV/TLC $\geq 40 \%,{ }^{10}$ or 2 ) the post-bronchodilator (post-BD) value of $R_{5}$ $\mathrm{R}_{20} \geq 0.075 \mathrm{kPa} \cdot \mathrm{L}^{-1} \mathrm{~s}^{11}$

\section{Statistical analyses}

The sample size was calculated based on previous studies that reported the proportions of SAD in patients with FAO-asthma and COPD of $60 \%$ and $74 \% .{ }^{17,18}$ By assuming a proportion of SAD in non-FAO asthma group was $30 \%$, with confidence interval of $95 \%$, power of $80 \%$, two-tailed a of 0.05 , and ratio between groups of $1: 1: 1$, the total sample size was 71 . Continuous variables were described as mean (SD) if data were normally distributed otherwise were described by median (range). Categorical variables were described as numbers and percentages. The Chi-squared test (or Fisher's exact test) was used for comparison of categorical variables between groups. One-way ANOVA (or Kruskal-Wallis test) was used for comparison of continuous variables between groups. Bonferroni method was used for multiple comparisons when data for each group had approximately normal distribution; otherwise, Wilcoxon rank-sum (Mann-Whitney) test was used. Linear regression analysis was used to assess the association between diagnosis and pulmonary function parameters, adjusted for confounding factors (such as age, sex and pack of smoking). Logistic regression analysis was used to determine the association between diagnosis group and SAD, adjusted 
for confounding factors. A $p$-value of 0.05 was considered statistically significant. In multiple comparisons, the adjusted level of significance $\left(a^{*}\right)$ was estimated by dividing the level of significance by number of comparisons $\left(\alpha^{*}=0.05 / 3=0.017\right)$ for comparing the associated $p$-value. All analyses were performed using STATA version 14.0 (Stata Corporation, College Station, TX, USA).

\section{Results}

A total of 73 patients [27 newly diagnosed non-FAO asthma (naïve to anti-asthma treatment), 24 FAO-asthma, and 22 stable COPD] were analyzed. Clinical characteristics and baseline pulmonary function parameters among patients with non-FAO asthma, FAO-asthma and COPD are summarized in
Table 1. There were significant differences between asthmatic patients and COPD patients in terms of sex, age, and smoking history. In FAO-asthma group, only 1 subject was prescribed budesonide DPI; the remaining were prescribed ICS/LABA in both FAO-asthma and COPD [ $\mathrm{n}=14(56 \%)$ for DPI, $\mathrm{n}=11$ (44\%) for MDI, and $n=11(52.4 \%)$ for DPI, $n=10(47.6 \%)$ for MDI, respectively]. There was no difference in distribution of drug formulation between FAO-asthma and COPD groups $(p=0.806)$. Allergic sensitization was shown in Table 1. Patients with FAO-asthma and COPD had significantly higher $\mathrm{RV}$ and RV/TLC ratio than those with non-FAO asthma (both $p<0.001)$. Patients with COPD had higher TLC than nonFAO asthma $(p=0.001)$, but not different from those with FAO-asthma.

Table 1. Comparison of characteristics and pulmonary function tests among asthma patients without- and with- FAO and COPD patients.

\begin{tabular}{|c|c|c|c|c|}
\hline Characteristic & $\begin{array}{l}\text { COPD } \\
n=22\end{array}$ & $\begin{array}{l}\text { FAO-Asthma } \\
\quad \mathbf{n}=\mathbf{2 4}\end{array}$ & $\begin{array}{l}\text { Non-FAO Asthma } \\
\qquad \mathbf{n}=27\end{array}$ & $\boldsymbol{P}$ \\
\hline \multicolumn{5}{|l|}{ Gender, n (\%) } \\
\hline Male & $21(95.45)$ & $3(12.50)$ & $5(18.52)$ & $<0.001$ \\
\hline Female & $1(4.55)$ & $21(87.50)$ & $22(81.48)$ & \\
\hline Age, years, mean (SD) & $73.86(7.53)$ & $68.13(7.18)$ & $60.59(8.19)$ & $<0.001$ \\
\hline Smoking (pack-year), median (range) & $17.5(10,120)$ & $0(0,9)$ & $0(0,10)$ & $<0.001$ \\
\hline Symptom score, mean (SD) & $12.00(6.83)$ & $20.54(3.32)$ & $21.54(4.76)$ & NA \\
\hline Symptomatic, n (\%) & $13(59.00)$ & $7(29.17)$ & $5(20.83)$ & 0.018 \\
\hline BMI, kg/m², mean (SD) & $22.65(4.27)$ & $24.29(3.98)$ & $25.68(4.80)$ & 0.062 \\
\hline Allergic sensitization, $\mathrm{n}(\%)$ & $8(40.00)$ & $12(50.00)$ & $14(51.85)$ & 0.701 \\
\hline \multicolumn{5}{|l|}{ Treatment } \\
\hline Long-acting $\beta 2$-agonist/ ICS, n (\%) & $14(63.60)$ & $24(92.30)$ & $0(0)$ & $<0.001$ \\
\hline \multicolumn{5}{|l|}{ Inhaled corticosteroid dose, $\mathrm{n}(\%)$} \\
\hline Low & $1(4.50)$ & $10(41.67)$ & $0(0)$ & $<0.001$ \\
\hline Medium & $5(22.70)$ & $6(25.00)$ & $0(0)$ & \\
\hline High & $10(45.50)$ & $9(37.50)$ & $0(0)$ & \\
\hline Leukotriene antagonist, n (\%) & $1(4.50)$ & $14(56.00)$ & $0(0)$ & $<0.001$ \\
\hline Theophylline, n (\%) & $3(13.60)$ & $3(12.50)$ & $0(0)$ & 0.188 \\
\hline Long-acting muscarinic antagonist, n (\%) & $18(81.80)$ & $5(20.83)$ & $0(0)$ & $<0.001$ \\
\hline Inhaled drug formulation & & & & 0.806 \\
\hline Dry-powder inhaler, n (\%) & $11(52.40)$ & $14(58.33)$ & NA & \\
\hline Metered-dose inhaler, n (\%) & $10(47.60)$ & $11(45.83)$ & NA & \\
\hline \multicolumn{5}{|l|}{ Spirometry } \\
\hline $\mathrm{FEV}_{1}, \%$ predicted, mean $(\mathrm{SD})$ & $65.86(18.95)^{\star}$ & $65.42(10.12)^{\dagger}$ & $84.52(13.16)$ & $<0.001$ \\
\hline FVC, \% predicted, mean (SD) & $88.32(13.23)$ & $89.79(15.83)$ & $91.59(16.15)$ & 0.753 \\
\hline $\mathrm{FEV}_{1} / \mathrm{FVC}, \%$ predicted, mean (SD) & $53.50(10.39)^{\star, *}$ & $61.92(10.32)^{\dagger}$ & $78.15(4.95)$ & $<0.001$ \\
\hline
\end{tabular}


Table 1. (Continued)

\begin{tabular}{|lcccc|}
\hline Characteristic & \multicolumn{1}{c}{$\begin{array}{c}\text { COPD } \\
\mathbf{n = 2 2}\end{array}$} & $\begin{array}{c}\text { FAO-Asthma } \\
\mathbf{n = 2 4}\end{array}$ & $\begin{array}{c}\text { Non-FAO Asthma } \\
\mathbf{n}=\mathbf{2 7}\end{array}$ & $\boldsymbol{P}$ \\
\hline Lung volumes & & & & \\
\hline TLC, \% predicted, mean (SD) & $96.95(12.42)^{*}$ & $93.67(13.34)^{\dagger}$ & $84.33(9.65)$ & 0.001 \\
\hline RV, \% predicted, mean (SD) & $95.23(25.62)^{*}$ & $105.71(22.59)^{\dagger}$ & $71.96(18.61)$ & $<0.001$ \\
\hline RV/TLC, \%, mean (SD) & $41.77(7.99)^{*}$ & $45.49(4.89)^{\dagger}$ & $31.93(8.13)$ & $<0.001$ \\
\hline RV/TLC, \% predicted, mean (SD) & $110.08(14.83)^{*}$ & $113.62(14.45)^{\dagger}$ & $83.92(20.15)$ & $<0.001$ \\
\hline DLCO/VA, \% predicted, mean (SD) & $80.1 \pm 20.96^{*}$ & $105.5 \pm 16.17$ & NA & $<0.001$ \\
\hline
\end{tabular}

Symptom score: ACT score in asthma, CAT score in COPD; symptomatic: ACT < 20 in asthma, CAT $\geq 10$ in COPD; BMI: body mass index; FEV 1 , FVC, and $\mathrm{FEV}_{1} / \mathrm{FVC}$ are the post-bronchodilator values. TLC and RV are pre- bronchodilator values. VA/TLC: ratio of alveolar ventilation (inert gas dilution) to total lung capacity; DLCO/VA: single-breath diffusing capacity of the lungs for carbon monoxide adjusted by alveolar ventilation ${ }^{*} P<0.017$ COPD vs. non-FAO asthma, ${ }^{\ddagger} p<0.017$ COPD vs. FAO-asthma, ${ }^{\dagger} p<0.001$ FAO-asthma vs. non-FAO asthma ( $p$-value of difference between group was significant with adjusted level of significance $(0.05 / 3=0.017)$, NA: not analysed.

\section{Impulse oscillometry parameters}

Pre- and post-bronchodilator values of IOS data among patients with non-FAO asthma and FAO-asthma and COPD are summarized in Table 2. Among asthmatic patients, there was higher pre-BD and post-BD values of $R_{5}$ and $R_{5}-R_{20}$ in FAO-asthma than in non-FAO asthma. Those with FAO also had significantly lower post-BD value of $\mathrm{X}_{5}(p=0.005)$ and higher post-BD value of $\mathrm{AX}(p=0.017)$, as well as higher post-BD value of Fres $(p=0.007)$ than in those without FAO. Compared with COPD group, FAO-asthma group had higher pre- $B D$ and post- $B D$ values of $R_{5}$ and $R_{20}$. As noted, these values including post-BD $R_{5}-R_{20}$ between non-FAO asthma and COPD groups were similar. (Table 2)

\section{Comparison of TLC, RV, and ratio of $R V / T L C$ among diag- nosis group and baseline characteristics}

The associations between diagnosis group and lung volume parameters, adjusted for confounding factors (age, sex and pack of smoking), are shown in Table 3. Multiple linear regression showed that the higher TLC, higher RV, and higher

Table 2. Comparison of impulse oscillometry (IOS) parameters among asthma patients without- and with-FAO and COPD patients.

\begin{tabular}{|c|c|c|c|c|}
\hline IOS parameters & $\begin{array}{l}\text { COPD } \\
n=22\end{array}$ & $\begin{array}{c}\text { FAO-Asthma } \\
n=24\end{array}$ & $\begin{array}{c}\text { Non-FAO Asthma } \\
n=27\end{array}$ & $P$ \\
\hline \multicolumn{5}{|l|}{ Pre-bronchodilator values } \\
\hline $\mathrm{R}_{5}, \mathrm{kPaL}^{-1} \mathrm{~s}$, mean $(\mathrm{SD})$ & $0.41(0.17)$ & $0.57(0.19)^{\ddagger}$ & $0.46(0.13)$ & 0.005 \\
\hline $\mathrm{R}_{20}, \mathrm{kPaL}^{-1} \mathrm{~s}$, mean $(\mathrm{SD})$ & $0.25(0.07)$ & $0.35(0.10)^{\ddagger}$ & $0.32(0.10)$ & 0.001 \\
\hline $\mathrm{R}_{5}-\mathrm{R}_{20}, \mathrm{kPaL}^{-1} \mathrm{~s}$, median (range) & $0.12(0.03,0.44)$ & $0.21(0.08,0.51)^{\dagger}$ & $0.13(0.06,0.26)$ & 0.024 \\
\hline $\mathrm{X}_{5}, \mathrm{kPaL}^{-1} \mathrm{~s}$, median (range) & $-1.67(-4.92,-0.75)$ & $-2.99(-8.28,-1.66)^{t, *}$ & $-2.20(-3.95,-1.15)$ & 0.008 \\
\hline $\mathrm{AX}, \mathrm{kPaL}^{-1}$, median (range) & $11.31(1.54,44.00)$ & $22.97(6.94,74.31)^{\dagger, *}$ & $10.93(4.08,23.38)$ & 0.004 \\
\hline Fres, Hz, mean (SD) & $22.11(6.58)$ & $23.96(5.30)^{\dagger}$ & $18.66(2.36)$ & 0.001 \\
\hline Raw, $\mathrm{kPaL}^{-1} \mathrm{~s}$, mean $(\mathrm{SD})$ & $0.23(0.13)$ & $0.32(0.12)^{*, \neq}$ & $0.22(0.08)$ & 0.004 \\
\hline Raw, \%predicted, mean (SD) & $163.00(83.03)$ & $207.75(78.77)^{\dagger}$ & $140.26(49.06)$ & 0.004 \\
\hline \multicolumn{5}{|l|}{ Post-bronchodilator values } \\
\hline $\mathrm{R}_{5}, \mathrm{kPaL}^{-1} \mathrm{~s}$, mean $(\mathrm{SD})$ & $0.38(0.16)$ & $0.55(0.18)^{t, \pm}$ & $0.42(0.13)$ & 0.001 \\
\hline $\mathrm{R}_{20}, \mathrm{kPaL}^{-1} \mathrm{~s}$, mean $(\mathrm{SD})$ & $0.25(0.07)$ & $0.36(0.10)^{\ddagger}$ & $0.31(0.10)$ & 0.002 \\
\hline $\mathrm{R}_{5}-\mathrm{R}_{20}, \mathrm{kPaL}^{-1} \mathrm{~s}$, median (range) & $0.10(0.003,0.39)$ & $0.17(0.08,0.47)^{\dagger}$ & $0.11(0.03,0.23)$ & 0.007 \\
\hline $\mathrm{X}_{5}, \mathrm{kPaL}^{-1} \mathrm{~s}$, median (range) & $-1.73(-5.78,-9.61)$ & $-2.57(-8.56,-1.68)^{\dagger}$ & $-1.85(-3.27,-0.89)$ & 0.005 \\
\hline $\mathrm{AX}, \mathrm{kPaL}^{-1}$, median (range) & $10.02(0.92,53.29)$ & $13.24(6.52,82.11)^{\dagger}$ & $8.63(2.40,22.02)$ & 0.017 \\
\hline Fres, $\mathrm{Hz}$, mean $(\mathrm{SD})$ & $20.43(6.93)$ & $22.53(4.57)^{\dagger}$ & $17.03(2.94)$ & 0.007 \\
\hline
\end{tabular}

Symptom score in COPD assessed by CAT score, and in asthma assessed by ACT score, ${ }^{*} p<0.017$ COPD vs. non-FAO asthma, ${ }^{*} p<0.017$ COPD vs. FAO-asth$\mathrm{ma},{ }^{\dagger} p<0.017 \mathrm{FAO}$-asthma vs. non-FAO asthma, ( $p$-value of difference between group was significant with adjusted level of significance $(0.05 / 3=0.017)$. 
Table 3. The association between diagnosis group and increased TLC, RV, and RV/TLC ratio after adjustment for significant covariates.

\begin{tabular}{|c|c|c|c|c|c|c|}
\hline \multirow{2}{*}{ Characteristics } & \multicolumn{2}{|c|}{$\begin{array}{c}\text { TLC } \\
\text { (\% predicted) }\end{array}$} & \multicolumn{2}{|c|}{$\begin{array}{c}\text { RV } \\
\text { (\% predicted) }\end{array}$} & \multicolumn{2}{|c|}{$\begin{array}{c}\text { RV/TLC } \\
(\%)\end{array}$} \\
\hline & Coef. $(95 \%$ CI $)$ & $\boldsymbol{P}$ & Coef. $(95 \%$ CI $)$ & $\boldsymbol{P}$ & Coef. $(95 \% \mathrm{CI})$ & $P$ \\
\hline \multicolumn{7}{|l|}{ Diagnosis } \\
\hline COPD & $12.62(5.86,19.38)$ & $<0.001$ & $23.26(10.54,35.99)$ & 0.001 & $6.08(1.13,11.03)$ & 0.017 \\
\hline FAO-Asthma & $9.33(2.73,15.94)$ & 0.006 & $33.74(21.32,46.17)$ & $<0.001$ & $11.38(7.13,15.63)$ & $<0.001$ \\
\hline Non-FAO Asthma & 0 & & 0 & & 0 & \\
\hline Age & & & & & $0.28(0.06,0.50)$ & 0.012 \\
\hline
\end{tabular}

Coef: coefficient (analysed by multiple linear regression)

RV/TLC ratio were independently associated with COPD and FAO-asthma diagnosis. The higher RV/TLC ratio was not only independently associated with COPD and FAO-asthma diagnosis, but also independently associated with increasing age.

Comparison of impulse oscillometry parameters among diagnosis group and baseline characteristics

The associations between diagnosis group and respiratory system resistance parameters as well as reactance parameters, adjusted for confounding factors (age, sex and pack of smoking), are shown in Table 4. Compared with FAO-asthma group, those with non-FAO had significantly lower value of $R_{5}-R_{20}(p=0.005)$, lower value of $A X$, and lower Fres (both $p<0.001$ ). Multiple linear regression showed that higher $R_{5}-R_{20}, A X$, and Fres were independently associated with FAO-asthma diagnosis (adjusted with age, sex and pack of smoking). The higher AX and Fres were not only independently associated with FAO-asthma diagnosis, but also was independently associated with pack of smoking.

\section{Prevalence of small airway dysfunction in patients with non- FAO asthma, FAO-asthma and COPD}

The prevalence of SAD among diagnosis group by RV/ TLC criterion was different $(95 \%, 59 \%$, and $15 \%$ in FAO-asthma, COPD, and non-FAO asthma, $p<0.001)$, but those were not observed by $\mathrm{R}_{5}-\mathrm{R}_{20}$ criterion $(95 \%, 68 \%$, and $77 \%$, respectively, $p=0.052$ ).

Table 4. The association between diagnosis group and impulse oscillometry values after adjustment for significant covariates.

\begin{tabular}{|c|c|c|c|c|c|c|}
\hline \multirow{2}{*}{ Characteristics } & \multicolumn{2}{|l|}{$\mathbf{R}_{5}$} & \multicolumn{2}{|l|}{$\mathbf{R}_{20}$} & \multicolumn{2}{|l|}{$\mathbf{R}_{5}-\mathbf{R}_{20}$} \\
\hline & Coef. $(95 \%$ CI $)$ & $P$ & Coef. $(95 \%$ CI $)$ & $P$ & Coef. $(95 \%$ CI $)$ & $P$ \\
\hline \multicolumn{7}{|l|}{ Diagnosis } \\
\hline COPD & $0.06(-0.06,0.19)$ & 0.332 & $0.01(-0.06,0.07)$ & 0.763 & $-0.03(-0.10,0.04)$ & 0.366 \\
\hline FAO-Asthma & $0.10(0.01,0.19)$ & 0.033 & $0.02(-0.02,0.04)$ & 0.338 & $0.08(0.02,0.13)$ & 0.005 \\
\hline Non-FAO Asthma & 0 & & 0 & & & \\
\hline \multicolumn{7}{|l|}{ Gender } \\
\hline Male & $-0.15(-0.26,-0.04)$ & 0.011 & $-0.11(-0.17,-0.05)$ & 0.001 & & \\
\hline Female & 0 & & 0 & & & \\
\hline \multirow{2}{*}{ Characteristics } & \multicolumn{2}{|l|}{$X_{5}$} & \multicolumn{2}{|l|}{$\mathrm{AX}$} & \multicolumn{2}{|l|}{ Fres } \\
\hline & Coef. $(95 \%$ CI $)$ & $P$ & Coef. $(95 \%$ CI $)$ & $P$ & Coef. $(95 \%$ CI) & $P$ \\
\hline \multicolumn{7}{|l|}{ Diagnosis } \\
\hline COPD & $-0.005(-0.77,0.76)$ & 0.990 & $-3.18(-12.57,6.22)$ & 0.502 & $0.68(-2.78,4.14)$ & 0.696 \\
\hline FAO-Asthma & $-1.20(-1.95,-0.44)$ & 0.002 & $13.90(6.70,21.10)$ & $<0.001$ & $5.30(2.65,7.96)$ & $<0.001$ \\
\hline Non-FAO Asthma & 0 & & 0 & & 0 & \\
\hline Smoking & & & $0.25(0.07,0.42)$ & 0.006 & $0.08(0.02,0.15)$ & 0.012 \\
\hline
\end{tabular}

Data are pre-bronchodilator values. Coef: coefficient (analysed by multiple linear regression) 
Table 5. The association between diagnosis and small airway dysfunction by different criteria after adjustment for covariates.

\begin{tabular}{|c|c|c|c|c|}
\hline \multirow{2}{*}{ Characteristics } & \multicolumn{2}{|c|}{ Post-BD $\mathrm{R}_{5}-\mathrm{R}_{20} \geq 0.075 \mathrm{kPa} \mathrm{L}^{-1} \mathrm{~s}$} & \multicolumn{2}{|c|}{$\mathrm{RV} / \mathrm{TLC} \geq \mathbf{4 0} \%$} \\
\hline & Coef. (95\% CI) & $P$ & Coef. $(95 \%$ CI) & $P$ \\
\hline \multicolumn{5}{|l|}{ Diagnosis } \\
\hline COPD & $1.16(0.64,2.10)$ & 0.630 & $2.98(1.05,8.45)$ & 0.041 \\
\hline FAO-Asthma & $1.35(1.04,1.74)$ & 0.026 & $6.35(2.43,16.58)$ & $<0.001$ \\
\hline Non-FAO Asthma & 1 & & 1 & \\
\hline \multicolumn{5}{|l|}{ Gender } \\
\hline Male & $0.72(0.45,1.15)$ & 0.173 & $0.94(0.63,1.39)$ & 0.758 \\
\hline Female & 1 & & 1 & \\
\hline Age & $0.99(0.97,1.01)$ & 0.086 & $1.00(0.98,1.02)$ & 0.855 \\
\hline Smoking & $1.01(0.99,1.01)$ & 0.064 & $1.01(1.01,1.02)$ & 0.009 \\
\hline
\end{tabular}

Post-BD: post-bronchodilator, OR: odds ratio (analysed by multivariate logistic regression)

Factors associated with small airway dysfunction determined by $R V / T L C$ ratio criterion and post-BD $R_{5}-R_{20}$ criterion

Diagnosis of FAO-asthma and COPD were associated with SAD determined by the RV/TLC ratio of $\geq 40 \%$ with the odds ratio (OR) of 6.35 (95\%CI, 2.43-16.58) and of 2.98 (95\%CI, $1.05,8.45)$, respectively. There was a weaker association of FAO-asthma diagnosis with SAD determined by the post-BD $\mathrm{R}_{5}-\mathrm{R}_{20}$ of $\geq 0.075 \mathrm{kPa} . \mathrm{L}^{-1} \mathrm{~s}$ (OR 1.35, 95\%CI 1.04-1.74) (Table 5).

\section{Allergic sensitization and small airway dysfunction}

Allergic sensitization was not different among groups (n $=14$ in non-FAO asthma, $\mathrm{n}=12$ in FAO-asthma, $\mathrm{n}=8$ in COPD, $p=0.701)$. It was not associated with SAD neither the RV/TLC criteria (OR 0.9, 95\%CI 0.52-1.41, $p=0.548$ ), nor the post-BD $\mathrm{R}_{5}-\mathrm{R}_{20}$ criteria (OR 1.2, 95\%CI 0.98-1.5, $p=0.085$ )

\section{Discussion}

This study revealed that the prevalence of SAD determined by the criteria of air trapping (RV/TLC ratio $\geq 40 \%$ ) and of increase in small airway resistance (post-BD $R_{5}-R_{20} \geq 0.075$ $\mathrm{kPa} . \mathrm{L}^{-1} \mathrm{~s}$ ) was significantly lower in asthmatic patients without FAO than in asthmatic patients and COPD who had FAO.

\section{Prevalence using plethysmography}

Whereas a previous study by Jain and colleagues ${ }^{17}$ using $\mathrm{RV} / \mathrm{TLC}$ ratio $>35 \%$ for SAD in asthmatic cohort reported the prevalence of SAD of $57 \%$, the prevalence of SAD in the present study with a higher cut-point of RV/TLC value was 95\% in FAO-asthma. The difference was due to the difference in asthma severity assessed by $\mathrm{FEV}_{1}$. Only $25 \%$ of patients in the study of Jain and colleagues ${ }^{17}$ had $\mathrm{FEV}_{1}<80 \%$ predicted, while all patients in our study had $\mathrm{FEV}_{1}<80 \%$ predicted in FAO-asthma group (mean post-BD $\mathrm{FEV}_{1} 65 \%$ predicted). Perez and colleagues ${ }^{19}$ conducted a study to determine the prevalence of hyperinflation in asthma by using air trapping (RV $>$ upper normal limit or FRC > 120\% predicted) as a marker of SAD. The prevalence of air trapping (determined by elevated RV and FRC) was higher in patients with a lower FEV
( $<60 \%$ predicted) compared to those with a higher $\mathrm{FEV}_{1}(>$ $80 \%$ predicted), (78\% for RV > upper normal limit and $70 \%$ for FRC > $120 \%$ predicted vs. $34 \%$ and $40 \%$, respectively). We found that $15 \%$ of newly diagnosed asthmatic patients who had $\mathrm{FEV}_{1}>80 \%$ predicted had abnormal $\mathrm{RV} / \mathrm{TLC}$ ratio $(\geq$ $40 \%$ ), less than that was previously reported by Perez et al., ranging from $23 \%$ to $30 \% .{ }^{20}$ Altogether, this suggested that the greater contribution of SAD can be found either in patients with poorly-controlled asthma, but having normal expiratory flow, or in patients with well-controlled asthma, but having FAO.

In COPD, chronic airflow limitation is well known to be caused by a combination of both small airway disease and parenchymal destruction. ${ }^{13}$ These changes diminish the ability of the airways to remain open during expiration and lead to collapse of airway lumen and air trapping in severe COPD. ${ }^{21}$ The overall prevalence of RV/TLC $\geq 40 \%$ in our COPD was $59 \%$, which was not different from those of FAO-asthma. Due to the fact that an increasing age has a significant effect on the increase in absolute value of RV/TLC ratio, the fixed cut-off of the absolute value of RV/TLC ratio may be of limited use as a good parameter of SAD in elderly patients. The RV/TLC ratio expressed as \% predicted may be superior because it is independent of age.

\section{Prevalence using impulse oscillometry}

From the previous studies in mild-to-moderate asthma using $\mathrm{R}_{5}-\mathrm{R}_{20} \geq 0.030 \mathrm{kPa} . \mathrm{L}^{-1} \mathrm{~s}$ for diagnosis of $\mathrm{SAD}$, the authors reported the prevalence of SAD ranging from 47 to $70 \% .^{22,23}$ Manoharan and colleagues ${ }^{23,24}$ assessed the relationship between SAD and asthma control in which a higher cut-point of $\mathrm{R}_{5}-\mathrm{R}_{20}$ of $\geq 0.1 \mathrm{kPa} . \mathrm{L}^{-1} \mathrm{~s}$ was used, and the prevalence of SAD was lower with the figure of $42 \%$. In their study, $94 \%$ and $44 \%$ of the patients were prescribed inhaled corticosteroid (mean dosage of $800 \mu \mathrm{g} \mathrm{BDP}$ ) and inhaled long-acting beta- 2 agonists, respectively. In the present study, a cut-point of $\mathrm{R}_{5}-\mathrm{R}_{20}$ in the intermediate value $\left(0.075 \mathrm{kPa} . \mathrm{L}^{-1} \mathrm{~s}\right)$ was chosen, ${ }^{11}$ and the prevalence of SAD was $77 \%$ in non-FAO asthma and $95 \%$ in FAO-asthma. We used the post-BD values to ensure the 
maximal bronchodilation in order to confirm the presence of airway obstruction. In addition to respiratory resistance, AX and Fres in non-FAO asthma were different from those in FAO-asthma. A recent study by Lui and colleagues ${ }^{25}$ reported that $\mathrm{AX}$ of $>1.07 \mathrm{kPa} / \mathrm{L}$ and Fres of $>12.65 \mathrm{~Hz}$ had high sensitivity, but low specificity for diagnosis of SAD in asthma (sensitivity $96 \%$ and $94 \%$, specificity $61 \%$ and $51 \%$, respectively). In our study, the combination of $\mathrm{R}_{5}-\mathrm{R}_{20}, \mathrm{AX}$ and Fres was not better than $R_{5}-R_{20}$ alone for diagnosis of SAD (data not shown). We thought that because increase in AX and Fres can be found in not only the abnormal small airway function but also in the reduced peripheral lung tissue compliance.

For IOS parameter of small airway resistance, there was a significant higher post-BD $\mathrm{R}_{5}-\mathrm{R}_{20}$ value for FAO-asthma than non-FAO asthma. For other IOS parameters, there were associations between the greater reduction of $\mathrm{X}_{5}$ value as well as the higher AX, the higher Fres and the diagnosis of FAO-asthma after adjustment for sex and pack of smoking. These observations were in contrast with the study of Williamson and colleagues, ${ }^{26}$ in which the authors enrolled younger asthmatics without FAO, asthmatics with FAO, and COPD patients, compared to ours ( 45 years vs. 59 years, 49 years vs. 61 years, and 68 years vs. 74 years, respectively). The reduction of peripheral lung tissue compliance in older subjects may affect the values of $\mathrm{X}_{5}, \mathrm{AX}$ and Fres. In this study both FAO-asthma and COPD groups are elderly, so the association between these parameters and FAO-asthma and smoking could be explained by a non-uniform distribution of ventilation due to small airway closure in which FAO-asthma and smokers would have. However, this association was not observed in COPD possibly because not only a non-uniformity of ventilation, but also a poor lung compliance as a result of moderate to severe airflow obstruction and poor lung compliance in COPD. These led to changes in $\mathrm{X}_{5}, \mathrm{AX}$ and Fres rather than small airway resistance. A previous study suggested that there was an enhanced dynamic airway narrowing on expiration in COPD. The authors recommended that analysis of the difference between inspiratory and expiratory $\mathrm{X}_{5}$ might be better than the whole-breath analysis. ${ }^{27} \mathrm{~A}$ further study is needed to elucidate the mechanisms.

The link between allergic sensitization and SAD was not demonstrated in this study. This could be that the definition, type of asthma, and method for assessment are different from a study including atopic asthma and utilizing the inflammatory biomarkers with inert gas washout technique. ${ }^{28}$

The strength of this study is that the non-FAO asthmatic patients whom asthma was newly diagnosed and had never been treated with anti-asthmatic drugs before physiologic measurement were enrolled. There was no difference in the distribution of drug formulation (i.e., dry-powder or metered dose inhaler) among the FAO-asthma and COPD groups, and there were no subjects treated with extrafine drug particle. Therefore, the number of patients with SAD was unlikely influenced by the effect of previous anti-asthmatic treatment. However, we acknowledge potential limitations. First, we did not include healthy subjects for comparison. Second, asthmatic patients whom we designated as having FAO showed a post-BD $\mathrm{FEV}_{1}$ (after $400 \mathrm{mcg}$ of salbutamol inhalation) of less than $80 \%$ predicted. This may overestimate the prevalence of
$\mathrm{SAD}$ in our study, compared to the studies including $\mathrm{FEV}_{1} /$ FVC $<0.7$, regardless of $\mathrm{FEV}_{1}$. Third, confirmatory tests for abnormal small airway function such as quantitative computed tomography were lacking. Lastly, the actual cumulative dosage of inhaled corticosteroids that may influence the small airways of patients was not taken into account.

In conclusion, $\mathrm{SAD}$ in non-FAO asthma (newly-diagnosed asthma) was less prevalent than in FAO-asthma and COPD by $R V / T L C$ ratio $\geq 40 \%$. In asthma, SAD should be suspected when the patients have uncontrolled asthma symptoms or fixed airflow obstruction.

\section{Acknowledgements}

The authors thank Mr. Stephen Pinder an English native speaker experienced in Medical English for English language proofreading and correction.

\section{Author Disclosure Statement}

The authors report no conflicts of interest.

\section{References}

1. Contoli M, Bousquet J, Fabbri LM, Magnussen H, Rabe KF, Siafakas NM, et al. The small airways and distal lung compartment in asthma and COPD: a time for reappraisal. Allergy. 2010;65:141-51.

2. Contoli M, Kraft M, Hamid Q, Bousquet J, Rabe KF, Fabbri LM, et al. Do small airway abnormalities characterize asthma phenotypes? In search of proof. Clin Exp Allergy. 2012;42:1150-60.

3. van der Wiel E, ten Hacken NH, Postma DS, van den Berge M. Small -airways dysfunction associates with respiratory symptoms and clinical features of asthma: a systematic review. J Allergy Clin Immunol. 2013; 131:646-57.

4. Crisafulli E, Pisi R, Aiello M, Vigna M, Tzani P, Torres A, et al. Prevalence of Small-Airway Dysfunction among COPD Patients with Different GOLD Stages and Its Role in the Impact of Disease. Respiration. 2017;93:32-41.

5. Burgel PR, Bourdin A, Chanez P, Chabot F, Chaouat A, Chinet T, et al. Update on the roles of distal airways in COPD. Eur Respir Rev. 2011;20: 7-22.

6. Jarenback L, Ankerst J, Bjermer L, Tufvesson E. Flow-Volume Parameters in COPD Related to Extended Measurements of Lung Volume, Diffusion, and Resistance. Pulm Med. 2013;2013:782052.

7. Usmani OS, Singh D, Spinola M, Bizzi A, Barnes PJ. The prevalence of small airways disease in adult asthma: A systematic literature review. Respir Med. 2016;116:19-27.

8. Piorunek T, Kostrzewska M, Cofta S, Batura-Gabryel H, Andrzejczak $\mathrm{P}$, Bogdanski $\mathrm{P}$, et al. Impulse oscillometry in the diagnosis of airway resistance in chronic obstructive pulmonary disease. Adv Exp Med Biol. 2015;838:47-52.

9. Kaczka DW, Dellaca RL. Oscillation mechanics of the respiratory system: applications to lung disease. Crit Rev Biomed Eng. 2011;39:337-59.

10. Diez Herranz A. RV/TLC\% ratio: alternative criteria of normality. Eur Respir J. 1995;8:1812-3.

11. Pisi R, Tzani P, Aiello M, Martinelli E, Marangio E, Nicolini G, et al. Small airway dysfunction by impulse oscillometry in asthmatic patients with normal forced expiratory volume in the 1st second values. Allergy Asthma Proc. 2013;34:e14-20.

12. Global Initiative for Asthma Executive Committee. Global Strategy for Asthma Management and Prevention. 2012 [Internet]. Bethesda: Global Initiative for Asthma; c2012 [cited 2012 Jan7]. Available from: http://www. ginasthma.org/.

13. Vestbo J, Hurd SS, Agusti AG, Jones PW, Vogelmeier C, Anzueto A, et al. Global strategy for the diagnosis, management, and prevention of chronic obstructive pulmonary disease: GOLD executive summary. Am J Respir Crit Care Med. 2013;187:347-65.

14. Oostveen E, MacLeod D, Lorino H, Farre R, Hantos Z, Desager K, et al. The forced oscillation technique in clinical practice: methodology, recommendations and future developments. Eur Respir J. 2003;22:1026-41. 
15. Morris JF. Spirometry in the evaluation of pulmonary function. West J Med. 1976;125:110-8.

16. Goldman HI, Becklake MR. Respiratory function tests; normal values at median altitudes and the prediction of normal results. Am Rev Tuberc. 1959;79:457-67.

17. Jain VV, Abejie B, Bashir MH, Tyner T, Vempilly J. Lung volume abnormalities and its correlation to spirometric and demographic variables in adult asthma. J Asthma. 2013;50:600-5.

18. Crisafulli E, Pisi R, Aiello M, Vigna M, Tzani P, Torres A, et al. Prevalence of small-airway dysfunction among COPD patients with different GOLD stages and its role in the impact of disease. Respiration. 2017;93:32-41.

19. Perez T, Chanez P, Dusser D, Vesque D, Devillier P. Prevalence of hyperinflation and its reversibility in asthma patients with poorly controlled disease or significant dyspnea. Eur Respir J. 2012;40:P2252.

20. Perez T, Chanez P, Dusser D, Devillier P. Small airway impairment in moderate to severe asthmatics without significant proximal airway obstruction. Respir Med. 2013;107:1667-74.

21. O'Donnell DE, Revill SM, Webb KA. Dynamic hyperinflation and exercise intolerance in chronic obstructive pulmonary disease. Am J Respir Crit Care Med. 2001;164:770-7.

22. Alfieri V, Aiello M, Pisi R, Tzani P, Mariani E, Marangio E, et al. Small airway dysfunction is associated to excessive bronchoconstriction in asthmatic patients. Respir Res. 2014;15:86.
23. Anderson WJ, Zajda E, Lipworth BJ. Are we overlooking persistent small airways dysfunction in community-managed asthma? Ann Allergy Asthma Immunol. 2012;109:185-9.e2.

24. Manoharan A, Anderson WJ, Lipworth J, Lipworth BJ. Assessment of spirometry and impulse oscillometry in relation to asthma control. Lung. 2015;193:47-51.

25. Liu L, Liu W, Liu C, Wang D, ZhaoJ, Wang J, et al. Study on small airway function in asthmatics with fractional exhaled nitric oxide and impulse oscillometry. Clin Respir J. 2018;12:483-90.

26. Williamson PA, Clearie K, Menzies D, Vaidyanathan S, Lipworth BJ. Assessment of small-airways disease using alveolar nitric oxide and impulse oscillometry in asthma and COPD. Lung. 2011;189:121-9.

27. Paredi P, Goldman M, Alamen A, Ausin P, Usmani OS, Pride NB, et al. Comparison of inspiratory and expiratory resistance and reactance in patients with asthma and chronic obstructive pulmonary disease. Thorax. 2010;65:263-7.

28. Haccuria A, Van Muylem A, Malinovcshi A, Doan V, Michils A. Small airway dysfunction: the link between allergic rhinitis and allergic asthma. Eur Respir J. 2018; 51:1701749. 